\title{
El patrimonio culinario como generador de industrias creativas y culturales: el caso de la plaza de mercado de Riosucio, Caldas, Colombia*
}

\section{Resumen}

La gastronomía tradicional además de conformar una parte significativa del patrimonio material e inmaterial de una sociedad constituye un escenario con un potencial importante en el desarrollo de industrias creativas y culturales comprometidas con la protección y promoción de la diversidad cultural. A partir de este marco conceptual este artículo tiene como objetivo proyectar/visibilizar la plaza de mercado de Riosucio Caldas, Colombia, como un escenario de prácticas culinarias capaz de articular las tradiciones y saberes de las cocinas tradicionales con el crecimiento económico. El enfoque metodológico tiene un carácter cualitativo que (a través de procesos de diálogo con la misma comunidad) presenta una realidad Ilena de valores históricos, sociales, simbólicos y estéticos que al ser analizados dieron como resultado la caracterización de esta Plaza como espacio de valor patrimonial con un potencial valioso en la generación de economías creativas, por la gran variedad de manifestaciones resultantes de la pluralidad de culturas que allí se encuentran entrelazadas por prácticas sociales y factores como el trabajo colectivo, la cooperación y un sistema culinario lleno de sincretismos que imprimen a esta Plaza una identidad legítima construida y enriquecida durante siglos. Como conclusión se resalta la necesidad de estrategias que promuevan en esta Plaza la recuperación arquitectónica; su sostenibilidad social, cultural y económica de manera vinculante; la socialización de sus saberes; la promoción de su valor patrimonial; y la transmisión de su legado a las generaciones venideras en un marco de trabajo que estimule la cooperación de actores públicos y privados, multisectoriales y multidisciplinares.
Tania Catalina Delgado

$\mathrm{PhD}$ in Design and Technologies Exploitation for the Cultural Heritage. Investigadora independiente Correo electrónico:

taniacatadelgado@gmail.com 응 orcid.org/0000-0003-0892-1296

Google Scholar

Ayda Nidia Ocampo Serna PhD en Diseño y Creación Profesora Universidad de Caldas. Manizales, Colombia

Correo electrónico: ayda.ocampo@ucaldas.edu.co @ orcid.org/0000-0001-6438-6756 Google Scholar

Recibido: marzo 23 de 2019 Aprobado: noviembre 19 de 2020

Palabras clave:

Cultura Culinaria, Economía Creativa, Industria Cultural, Patrimonio Cultural, Plaza de Mercado.

\footnotetext{
* Este artículo se basa en los resultados de la tesis de doctorado en Diseño y Creación de la Universidad de Caldas, Colombia, titulada: El diseño para la valoración del patrimonio. Cultura culinaria plaza de mercado Riosucio, Caldas, Colombia. Autora: Ayda Nidia Ocampo Serna. Dirección: Tania Catalina Delgado.
} 


\section{Culinary heritage as a generator of creative and cultural industries: the case of the Riosucio market place (Plaza), Caldas, Colombia}

\begin{abstract}
Traditional gastronomy, in addition to constitute a significant part of the tangible and intangible heritage of a society, constitutes a scenario with significant potential in the development of creative and cultural industries committed to the protection and promotion of cultural diversity. Based on this conceptual framework, this article aims to project and make visible the market place of Riosucio Caldas, Colombia, as a scenario of culinary practices capable of articulating the traditions and knowledge of traditional cuisines with economic growth. The methodological approach has a qualitative character that (through dialogue processes with the community) presents a reality full of historical, social, symbolic and aesthetic values that, when analyzed, resulted in the characterization of this Plaza as a space of heritage value with an important potential in the generation of creative economies, due to the great variety of manifestations resulting from the plurality of cultures that are intertwined there by social practices and factors such as collective work, cooperation and a culinary system full of syncretism that imprint this Plaza a legitimate identity built and enriched over centuries. In conclusion, the need for strategies that promote architectural recovery in this Plaza is highlighted as well as its social, cultural and economic sustainability in a binding way, the socialization of its knowledge, the promotion of its patrimonial value, and the transmission of its legacy to future generations in a framework that encourages the cooperation of public and private, multisectoral and multidisciplinary actors.
\end{abstract}

Key words:

Culinary Culture; Creative Economy; Cultural Industry; Cultural heritage; Marketplace. 


\section{Introducción}

Actualmente, en la transformación de las diferentes dinámicas de la vida diaria, surge un potencial de la industria y los mercados que convierte los modos de vida en un — modus vivendi - acelerado, donde — en muchos casos — se dejan de percibir aspectos esenciales de las vivencias cotidianas: comportamientos, costumbres y lugares que son base de la idiosincrasia de las personas. En nuestros días, existe el riesgo de no proteger los espacios que no conforman las dinámicas actuales de las ciudades, lugares como parques, edificios antiguos e inclusive las plazas de mercado, los cuales son vistos sólo como sitios que se deben restaurar o transformar para estar acorde con el progreso y, lastimosamente, no son valorados desde su calidad cultural, sus costumbres, saberes, conocimientos ancestrales y el aporte que hacen a la construcción de realidades sociales.

La plaza de mercado como lugar de comercio mediada por prácticas culturales, posee el testimonio de la vida diaria, forjada a través de la historia, las tradiciones y el devenir del tiempo; allí se concentra el fruto del trabajo de familias a través de los productos que llegan del campo y las comidas que se ofrecen al público visitante. Con el pasar de los años, las plazas de mercado han caído en el olvido, con menos recursos para invertir, lo cual se ve reflejado en el estado de deterioro y en el incumplimiento de algunas normas sanitarias ambientales en muchas de ellas. Además, se han visto en la necesidad de reinventarse para competir con las nuevas dinámicas del mercado, dadas en parte por las grandes cadenas de supermercados que se han acoplado alrededor de ellas. Pese a todas estas problemáticas, las plazas de mercado reflejan una cultura culinaria que merece ser valorada y que hace parte del análisis de este escrito, el cual trata de develar el valor cultural de algunos alimentos y el valor artesanal de sus cocinas tradicionales como parte de un patrimonio culinario regional que es inmaterial por ser resultado de usos, costumbres, conocimientos, legados y tradiciones. 
Muestra de lo anterior es la plaza de mercado del municipio de Riosucio (Caldas) (Imágenes 1a, 1b), la cual representa una riqueza cultural tanto material como inmaterial con manifestaciones como la cultura culinaria, reconocida por su valor ancestral y que refleja los conocimientos culinarios trasmitidos por generaciones de familias a través de la práctica de distintos métodos de preparación y cocción, donde se mantiene la esencia de las etnias indígenas provenientes de este municipio, quienes otorgan saberes con productos que, en su mayoría, provienen de sus propios cultivos, lo cual ayuda a fomentar la cooperación y el intercambio de productos para un beneficio colectivo.

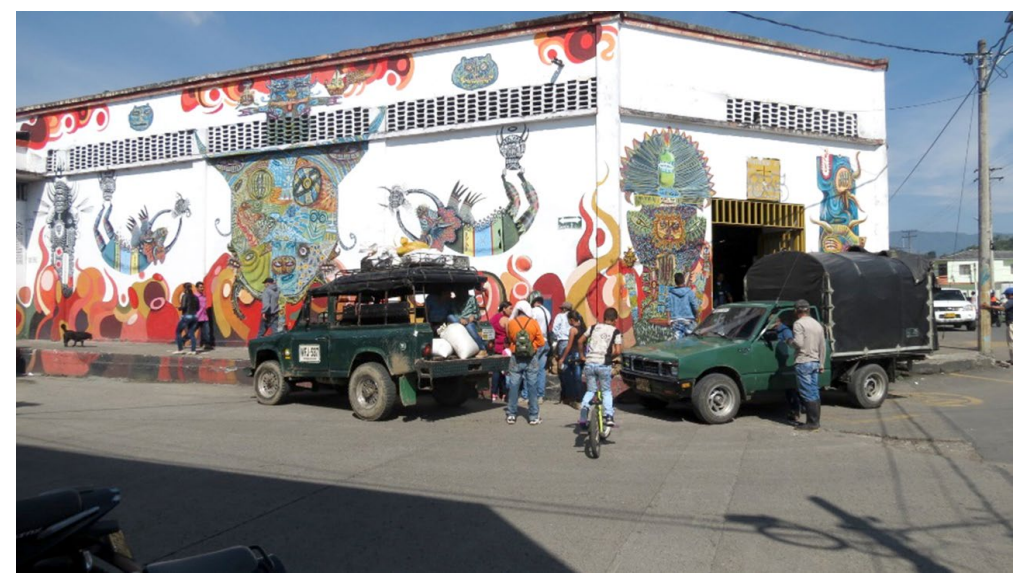

Imagen 1a. Vista exterior Plaza de Mercado Riosucio Caldas. Fuente: Ayda Nidia Ocampo Serna. 


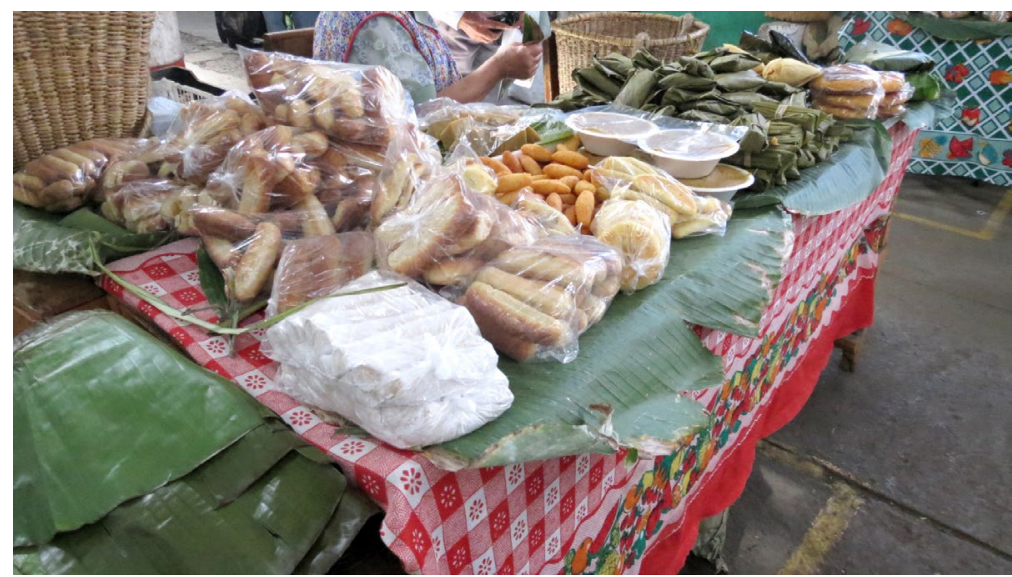

Imagen 1b. Vista interior Plaza de Mercado Riosucio, Caldas. Fuente: Ayda Nidia Ocampo Serna.

A pesar de la importancia cultural que tienen estas cocinas tradicionales, hasta el momento son pocos los proyectos y estudios que ayuden a su valoración y salvaguarda desde el punto de vista inmaterial, ya que cuando se encuentran, generalmente se enfocan en proyectos de desarrollo desde la parte material (arquitectónica), sin tener en cuenta que estos espacios son también parte del patrimonio cultural culinario', ya que en ellos existen una variedad de manifestaciones étnicas y culturales resultantes de su actividad comercial. Es por ello que se detecta la necesidad de "hacer visible" los valores que poseen las plazas de mercado y su potencial para transformarse en economía creativa en busca de la inclusión y el bienestar social, todo esto con el objetivo de concientizar a la sociedad del valor culinario de estos "lugares de olvido" que son importantes para nuestra sociedad, no sólo por su historia sino también por su riqueza estética particular y su significado simbólico cultural tanto material como inmaterial. 


\section{Método}

La investigación incorporó un enfoque de carácter cualitativo, debido a su interés en estudiar una realidad social a través de la misma comunidad y del análisis de su contexto (Hernández, 2006). La indagación se enfocó en la actividad humana que constituye la cultura culinaria tradicional. De esta manera, se buscó explicar las dinámicas de la cocina con base en la experiencia cotidiana, de forma que se pudieran capturar los significados atribuidos a las prácticas culinarias por quienes interactúan en la plaza de mercado. Con esto, se propuso identificar los alimentos que hacen parte de la cultura culinaria del municipio y, además, estructurar una estrategia de visibilización para aportar al conocimiento y valoración de la riqueza culinaria presente en las cocinas de las plazas de mercado de Riosucio (Caldas). Así, para entender sus recetas y preparaciones, fue necesario ejecutar las siguientes fases en el desarrollo de la investigación:

Trabajo en campo: la investigación se llevó a cabo entre los años 2016 y 2017. De acuerdo con los criterios de la investigación, la población entrevistada corresponde a personas con saber culinario, (1) cocineras y cocineros que laboran en las cocinas de la plaza de mercado; (2) personas que visitan la plaza. (3) habitantes del municipio. Instrumentos: entrevistas estructuradas, entrevistas semiestructuradas, recolección de información asociada con elaboración y preparación de alimentos, recolección de información asociada al concepto del valor culinario. 


\title{
Discusión
}

\section{El Patrimonio Cultural Como Motor de Desarrollo Territorial}

\begin{abstract}
Si bien en los últimos años se ha visibilizado el aporte de la cultura a la producción de riqueza, la diversificación de la economía nacional y la generación de ingresos y empleo, su importancia cobra mayor significado cuando se observa que las expresiones culturales, manifestadas en bienes y servicios culturales, afianzan valores sociales e inciden en la construcción de identidades diversas y el fortalecimiento de la ciudadanía. (Montoya \& Piedra, 2017, p.19).
\end{abstract}

El patrimonio inmaterial presente en las cocinas tradicionales de la plaza de mercado de Riosucio (Caldas), constituye un escenario de recursos capaces de estructurar, desde su carácter creativo y cultural, industrias con el potencial de promover el fortalecimiento de las mismas manifestaciones patrimoniales y el empoderamiento de la comunidad (portadora de tradiciones) como agentes activos de su propio desarrollo territorial. De esta manera, es posible proyectar industrias creativas y culturales desde el interior de comunidades ricas en tradiciones culinarias, como en el caso que se presenta en la mencionada plaza de mercado, que aprovechen el conocimiento y los oficios que se han perfeccionado a lo largo de varias generaciones que, además de continuar vivos, contienen características identitarias únicas que abren espacios en la economía con un potencial significativo al promover la inclusión social, la generación de empleos y el crecimiento económico (Throsby, 2001).

El reconocimiento del valor del Patrimonio Cultural no se limita a la esfera cultural; actualmente sus recursos han evidenciado diversos aspectos que abren la posibilidad de convertirlo en agente activo de desarrollo territorial, tal como se afirmó en la Conferencia Intergubernamental sobre Políticas para el Desarrollo organizada por la UNESCO en 1998 (Estocolmo). El desarrollo sostenible y el florecimiento de la cultura son aspectos interdependientes (UNESCO, 1998). Esta posición fue confirmada más adelante por la UNCTAD 
(Conferencia de las Naciones Unidas para el Comercio y el Desarrollo) a través de su reporte de Economía Creativa del 2013 (UNCTAD, 2013), el cual reúne estadísticas internacionales sobre el comercio mundial de bienes y servicios creativos y culturales, al enfatizar que la cultura es un motor y facilitador de desarrollo, no sólo económico sino también social y por supuesto cultural.

La oportunidad de entrelazar la economía y la cultura ha permitido superar paradigmas entre estas dos esferas (que por lo general se han mantenido separadas) para desencadenar procesos que generan crecimiento económico (Howkins, 2002), pero sobre todo beneficios sociales y culturales. De esta manera, se ha construido el concepto de la Economía Creativa, que reconoce los recursos creativos y culturales de un territorio como su plataforma de base, su fuente inagotable y su principal insumo de desarrollo y fortalecimiento. Este modelo económico reúne los sectores que se caracterizan por desarrollar productos y servicios con altos contenidos simbólicos (creativos y culturales) y que a través de su circulación no solamente activan la economía de un sector, sino también promueven experiencias emocionales que van más allá de aspectos utilitarios simples, profundamente relacionados con la valoración y un acercamiento responsable a la Cultura de un territorio.

\section{La cultura culinaria como patrimonio cultural}

Actualmente y a nivel mundial, el instrumento de mayor importancia en relación con el patrimonio es la Convención para la Salvaguardia del Patrimonio Cultural Inmaterial, aprobada por la Conferencia General de la UNESCO (2003). Esta nació debido a la necesidad de salvaguardar el patrimonio y como un esfuerzo por promover y proteger la diversidad cultural. A través de dicha Declaración, la comunidad internacional registró la necesidad de reconocer la importancia de las manifestaciones y expresiones culturales que hasta entonces no tenían un marco jurídico y programático que las protegiera, pasando luego 
a que los países miembros de la UNESCO organizaran sus propias políticas. La Convención para la Salvaguardia del Patrimonio Cultural Inmaterial, declaró que este patrimonio se puede manifestar en ámbitos como "tradiciones orales, artes del espectáculo, usos sociales, rituales, actos festivos, conocimientos y prácticas relativos a la naturaleza y el universo, y saberes y técnicas vinculados a la artesanía tradicional" (UNESCO, 2003).

Todas estas manifestaciones, detectadas como patrimonio cultural inmaterial, se ven reflejadas en las cocinas tradicionales, las cuales son el resultado de necesidades como la alimentación, dondesu valor hace parte del reconocimiento de la diversidad biocultural para el desarrollo de los pueblos. Existen, en la actualidad, muchos ejemplos de cómo la cultura alimentaria es tema central de discusión en escenarios locales, regionales, nacionales e internacionales. La cultura alimentaria actúa como un nuevo fenómeno económico, político, ecológico, social y cultural, respondiendo así a formas de organización dentro de las políticas públicas de los países. Existen varios ejemplos de países que, dentro de sus políticas nacionales, han visto en la cultura culinaria un punto de encuentro para el desarrollo sostenible de sus economías y de la calidad de vida de sus pueblos, uno de ellos es la Slow Food, movimiento que nació en París en 1989, cuyo fundador es el sociólogo italiano Carlos Petrini, quien en entrevista a Radio Francia Internacional con Orlando Torricelli afirma que la idea era contraponerse a la filosofía que valoriza la diversidad de las culturas alimentarias respecto a la homologación y la uniformización:

"Nuestro espíritu cambió profundamente porque empezamos a interesarnos por la producción de alimentos, por la agricultura y el savoir faire del pequeño artesano alimentario, más que por los grandes chefs y la gran cocina; lo que nos permitió llegar a más de 170 países" (Torricelli, 2014)

De esta forma se consolidó Slow Food. Una red de más de seis mil comunidades, las cuales han permitido desarrollar políticas ambientales y sociales como asociación eco-gastronómica sin ánimo de lucro. Esta institución contrarresta 
la "fast food" y la "fast life", lucha por las tradiciones gastronómicas locales, combate la desnutrición y, actualmente, cuenta con más de 100.000 miembros en todo el mundo que promueven una nueva lógica de producción y educación alimentaria.

Por otra parte, desde países como Bélgica, Finlandia, Italia, Países Bajos y Turquía nace la iniciativa de Grandma's Desing ${ }^{2}$, como una invitación a conectarse con el patrimonio y las diferentes identidades culturales a través de la cultura alimentaria. En esta iniciativa, quince abuelas fueron filmadas y entrevistadas mientras preparaban una receta de cocción típica de su país o región, con el objetivo no sólo de preservar sus tradiciones, sino también de darles vida con una nueva interpretación, teniendo en cuenta las condiciones cambiantes de la sociedad actual.

Uno de los principales representantes de la cultura culinaria en América Latina es Perú, el cual se muestra al mundo por su "cocina peruana" a través de una política de desarrollo de los sectores público y privado. Esto le ha permitido modernizar ciertos tipos de producción agrícola, valorizar sus tradiciones culinarias regionales y lograr el reconocimiento de la cocina peruana ${ }^{3}$. La llamada revolución gastronómica peruana (Lauer \& Lauer, 2006), con más de diez años, ha permitido elevar la cocina tradicional como arte culinario a estándares comerciales internacionales. Es por esto que Perú cuenta con "Ministra", una feria gastronómica de chefs donde participan más de trecientas comunidades campesinas de todo el país. Quienes han contribuido a todo este reconocimiento de la gastronomía peruana han sido los chefs del Perú, en especial Gastón Acurio, un chef que ha creado escuelas de cocina para formar a los jóvenes campesinos en el oficio culinario, haciendo un trabajo muy importante que relaciona a la cocina con la agricultura a través de

\footnotetext{
${ }^{2}$ http://www.grandmasdesign.com/

${ }^{3}$ Quizá con la influencia de las coyunturas internacionales vinculadas al patrimonio cultural, en 2007, y mediante Resolución Directoral, el Instituto Nacional de Cultura declara la cocina peruana como patrimonio cultural de la nación (Arista Zerga, 2015, p. 197).
} 
intercambios entre grandes chefs y pequeños productores. Estos hechos han permitido el reconocimiento de la cultura culinaria del Perú.

Finalmente, reconocemos que Colombia es un país que cuenta con una gran diversidad cultural, las riquezas de $\mathrm{PCl}$ asociadas a la cocina están inmersas en dicha diversidad y hacen parte de un sistema de significados y afirmación de identidades que permiten la cohesión social. Según la política de cocinas tradicionales en Colombia (Ministerio de Cultura de Colombia, 2012), las cocinas tradicionales son el resultado de un largo proceso histórico y colectivo, expresan la relación con el contexto ecológico y productivo del cual se obtienen los productos que se llevan a la mesa, cumplen una función cohesionadora ya que generan sentimientos de identidad, pertenencia y continuidad histórica. Alrededor de ellas se reúnen las familias, se fomentan la asociatividad y valores como la generosidad y la solidaridad entre las personas, $y$, finalmente, cada sistema culinario, con sus recetas, platos y formas de consumo, remite a una tradición y a un universo simbólico particular, así como a un "orden culinario" que contiene reglas de comportamiento, prescripciones y prohibiciones culinarias, rituales y estéticas. En este sentido, la cultura culinaria se constituye como un factor de identidad, ya que representa las tradiciones de una comunidad. Además, es un vehículo de conocimientos, no solo alrededor de la cocina sino también en relación con los productos agrícolas y su respectivo manejo. Es por esto que la política de cocinas tradicionales en Colombia tiene como objetivo general valorar y salvaguardar la diversidad y riqueza cultural de los conocimientos, prácticas y productos alimenticios de las cocinas tradicionales de Colombia como factores fundamentales de la identidad, pertenencia y bienestar de la población (Ministerio de Cultura de Colombia, 2012).

Pero surge la pregunta: ¿Cómo reconocer, comprender y visibilizar esta cultura culinaria con miras a las industrias culturales, teniendo en cuenta su rol en 
términos económicos, sociales y culturales? Identificar el valor culinario de una comunidad significa reconocer en un grupo de personas valores sociales como el trabajo, la cooperación y la constancia para sostenerse con algo tan vital como el alimento. Debe tenerse en cuenta que es difícil valorar el conocimiento que ha sido invisibilizado y que, lastimosamente, sólo es posible proteger lo que se conoce y valora. En relación con este tema, es fundamental difundir los aspectos que componen el patrimonio cultural tanto material como inmaterial de una región, por ejemplo, a través de posibilidades políticas y/o económicas que favorezcan la inserción de las tradiciones en un contexto cultural, para el reconocimiento, la reivindicación y la valoración de la riqueza cultural de un territorio que se ha sostenido en el tiempo.

Si bien todo el discurso del patrimonio se ha centrado en ver cómo restaurar y proteger aquellos bienes u objetos materiales sobre los cuales ha pasado el tiempo con la necesidad de recuperar esa autenticidad histórica, vemos cómo ese discurso ha pasado también a revisar cómo proteger aquellas expresiones humanas en sus saberes, entre ellos el culinario, lo que hoy llamamos patrimonio inmaterial o patrimonio vivo contenido en las personas, sobre todo entendiendo que ambos son parte del patrimonio cultural de las comunidades y que, por ende, es necesario conservar. Incluso, en muchos de los casos, el patrimonio material es el resultado de saberes previos inmateriales, en primer lugar, el patrimonio cultural inmaterial se materializó gracias al patrimonio cultural material, y, en segundo lugar, la cultura inmaterial juega el papel vital dentro de la creación del patrimonio cultural tangible (Ito, 2003).

Esta proclamación de derechos y deberes sociales dentro de la Política Patrimonial, ha permitido una revisión de los valores que las comunidades poseen y que es el tema central de este escrito. Para Caraballo, por ejemplo, los valores patrimoniales, como parte de un complejo mayor de sistemas de valores sociales, son conceptos éticos, socialmente cambiantes, aceptados y deseados 
como ideales en un determinado contexto social e histórico (Caraballo, 2011). Los valores están inmersos en las relaciones sociales que ejercen las personas dentro de las comunidades. El valor, como concepto, expresa necesidades y significados sociales que hacen parte de la existencia de una comunidad, y el hecho de identificar estos valores en ella permite construir espacios de diálogo entre la comunidad que lo posee y aquella que lo valora, convirtiéndose en discurso de identidad colectiva, concepto reciproco entre el dar y recibir. El objetivo de interpretar los valores que una comunidad posee es el de mejorar la visión, dar respeto y comprensión a la manifestación y de la importancia que esta representa para su conservación, pero esta comprensión de valores debe estar en la mente no sólo del que la interpreta sino también en la del ciudadano común; es allí de donde parte la necesidad de una mejor comprensión por la conservación de la cultura culinaria y sus conocimientos ancestrales.

El intercambio cooperativo que se refleja en las acciones comerciales de las plazas de mercado, entendido éste como un encuentro de personas con beneficios mutuos, permite reconocer valores sociales que se repiten una y otra vez, en dinámicas de relaciones psicoafectivas, formales e informales, o simplemente de poder. Asimismo, los trabajos realizados se ejercitan en habilidades físicas que se convierten en un ritual desapercibido para muchos, conformado por: el respeto mutuo, la cooperación y la autoridad ganada. La plaza de mercado, como un espacio productor de rituales cooperativos, permite a los trabajadores afianzar valores sociales, tradiciones culturales, ligadas al uso de conocimientos, técnicas y herramientas, en pro de su bienestar social, económico y cultural. Convirtiéndose en maestros del hacer. Entonces Sennett (2012) nos dice:

He aquí, pues, tres modos de producir cosas plenas de implicación social. El ritmo del desarrollo de una habilidad física puede encarnar un ritual; los gestos entre personas pueden encarnar el triángulo social informal; el uso de la fuerza mínima puede encarnar la respuesta frente a quienes resisten o difieren. (p. 300) 
Estas palabras y muchas otras a las que Sennett se refiere en su libro Juntos, permiten reflexionar sobre la fuerza social que muchas comunidades poseen a través de sus tradiciones culturales y que merecen ser revisadas y valoradas.

\section{El Patrimonio Culinario en la generación de Industrias Creativas y Culturales}

Dentro de los recursos que hacen parte de la plataforma base de la Economía Creativa, encontramos el Patrimonio Culinario. Este, además de presentar un sistema de manifestaciones inmateriales con una riqueza cultural invaluable (en donde las tradiciones culinarias se convierten en un nodo articulador de prácticas sociales, manifestaciones artesanales, etc.), establece un escenario idóneo para el desarrollo de emprendimientos culturales-productivos al interior de las mismas comunidades, portadoras de estos saberes tradicionales (Ministerio de Cultura de Colombia, 2012).

Este escenario se fortalece a través del uso responsable de este Patrimonio, porque al respetar la precisión y la dedicación que requieren los oficios de las cocinas tradicionales se mantiene la esencia y autenticidad de sus productos culinarios, y también se potencializa su proyección como productos únicos e irrepetibles en mercados especializados (Miele \& Murdoch, 1999).

De esta manera, los emprendimientos culturales-productivos estructurados a partir del Patrimonio Culinario, reflejan la identidad de un territorio y promueven la conservación de la diversidad cultural, beneficios no monetarios que se esperan de cualquier Industria Creativa y Cultural (UNCTAD, 2013) ${ }^{4}$ al establecer, por medio de la circulación de sus productos y servicios, redes de diálogo entre culturas que contribuyan al conocimiento, valoración y respeto de otros modos de vida.

${ }^{4}$ Según la UNESCO, las Industrias Creativas y Culturales son "central in promoting and maintaining cultural diversity" . (Cano, Garzón, \& Poussin, 2000, pág. 12) 
Este escenario de emprendimiento evidencia el valor de estos oficios tradicionales, tanto al respecto de la memoria cultural de las comunidades, como en su bienestar social y económico. Así, al interior de las mismas comunidades portadoras de estos conocimientos, se motiva su activación y continua práctica que también favorecerá procesos de innovación y salvaguarda de las cocinas tradicionales, teniendo en cuenta que el patrimonio cultural inmaterial nunca permanece fosilizado, al contrario, cada generación lo enriquece para mantenerlo vivo y fortalecerlo; por eso es considerado un trabajo en proceso, evolutivo, acumulativo y estructurado ${ }^{5}$.

Promover este tipo de emprendimientos culturales-productivos asegura la salvaguardia del patrimonio cultural inmaterial (al interior de las mismas comunidades portadoras de tradiciones culinarias) que, de acuerdo con la UNESCO, significa "velar por que siga formando parte activa de la vida de las generaciones presentes y se transmita a las venideras" (UNESCO, 2003).

\section{La plaza de mercado como contenedor de la economía creativa}

Para citar un ejemplo de un espacio contenedor de economía creativa, nos remitimos a la plaza de mercado del Municipio de Riosucio, el cual está ubicado en el sector norte de la zona occidental de Caldas, Colombia; posee una extensión de 429,1 Km2, está conformado por 100 veredas, 2 corregimientos y 4 resguardos indígenas.

La economía de esta región está basada en la agricultura. Los cultivos que predominan son el café, la caña de azúcar, el plátano, el maíz, el cacao, la yuca, la arracacha y el fríjol. A su vez, el municipio posee una gran riqueza cultural que contiene un sinnúmero de costumbres y festividades que otorgan

Durante la primera sesión del Comité de Patrimonio Inmaterial de la UNESCO (2006), Ms Khalida Toumi (Ministra de Cultura en Argelia del 2002 al 2014) enfatizó sobre la importancia de reconocer al Patrimonio Inmaterial como: "always a work in progress, evolving, cumulative and structured". 
vida e identidad a esta región; esto gracias a que diferentes grupos humanos habitaron sus tierras: por una parte, colonos españoles que Ilegaron en 1590 y, por otra, alrededor de 1850 el municipio comienza a recibir la influencia antioqueña (Zapata Bonilla, 1997).

Esta población es famosa por "El Carnaval del Diablo" el cual es tradicional del país y fue declarado Patrimonio Cultural Inmaterial de la Nación con la resolución 1658 de 2011 del Ministerio de Cultura. El origen del Carnaval se remite a 1847, cuando se efectuó la unión entre los pobladores de Quiebralomo y La Montaña. Se lleva a cabo cada dos años en el mes de enero, donde el diablo es símbolo de reconciliación y perdón (Cámara de Comercio de Manizales, 1999) y se considera que es un espacio festivo que refleja ampliamente el folclor de la región, ya que incluye una mezcla de distintas creencias y culturas, resultado del mestizaje existente. Sin embargo, estas festividades constituyen un punto de inflexión para la visibilización de las tradiciones culinarias, esto teniendo en cuenta que las acciones estratégicas del municipio se orientan, en primera instancia, a posicionar de forma particular este evento, limitando la construcción de un sentido de legitimidad alrededor de las manifestaciones culinarias. No obstante, es de reconocer que todas estas manifestaciones suman a la diversidad cultural de Riosucio.

Económicamente, el reconocimiento de la cultura culinaria de la plaza es una opción laboral, una fuente de ingresos que va desde la elaboración y producción hasta la venta de los platos y/o productos. Esto se une al valor que algunas comidas, con cientos de años de antigüedad, que respetan ingredientes y procesos de elaboración, es el caso de algunos envueltos de maíz como nos lo narra María Clemencia Largo:

El Chiquichoque es de maíz trillado blanco, entonces nosotros para este que vendemos hoy (sábado) lo lavamos el domingo, o sea que se lava y se deja en agua hasta el martes que volvemos y le cambiamos el agua, lo ponemos al fogón a medio hervir y ya el jueves lo molemos y el viernes ya 
los preparamos. Pero bueno ese es el maíz curado, ya después lo molemos, después de juagarlo bien y ponerlo al fogón, ya lo batimos como batiendo natilla y ya lo envolvemos en la hoja de bijao. El chiquichoque tiene frijol, el frijol lo cocinamos y se muele y se le hace un hogadito y ya se lo echamos a la masita blanca y se envuelve y se pone a cocinar.

(...) La nalga de ángel es de maíz trillado blanco sin relleno (mismo proceso del chiquichoque). (...) La estaca es de maíz amarillo, maíz entero que se pela con ceniza para quitarle la cáscara del maíz, entonces se pela con ceniza de leña, se pone en una olla la ceniza, cuando está bien caliente le echamos el maíz, ya lo dejamos un rato y luego se lava (Comunicación personal, receta de cocina tradicional, marzo de 2017).

Este recetario, es una pequeña muestra de saberes culinarios que se combinan con otros envueltos de maíz, como son los envueltos de chócolo, tamales, arepa de chócolo (imágenes 2a, 2b) ,"viandas", "ogagato", "nalga de ángel", "Chik Chok", "estacas", natilla, buñuelos, empanadas, pandequeso montañero (imágenes 3a, 3b), productos alimenticios a base de colada de maíz tierno o maíz curado, con diferentes tipos de preparaciones, y que se pueden adquirir en esta plaza de mercado, lugar que refleja todo el valor gastronómico, parte del patrimonio culinario transmitido por las generaciones que han mantenido vivas las tradiciones de este lugar, donde las recetas son herencias familiares $y$, sus productos, son resultado del trabajo de toda una familia que comienza su ardua jornada laboral desde la madrugada, para poder comercializar los productos frescos y deliciosos el día sábado en la plaza, buscando complacer el paladar de propios y visitantes de la región. 


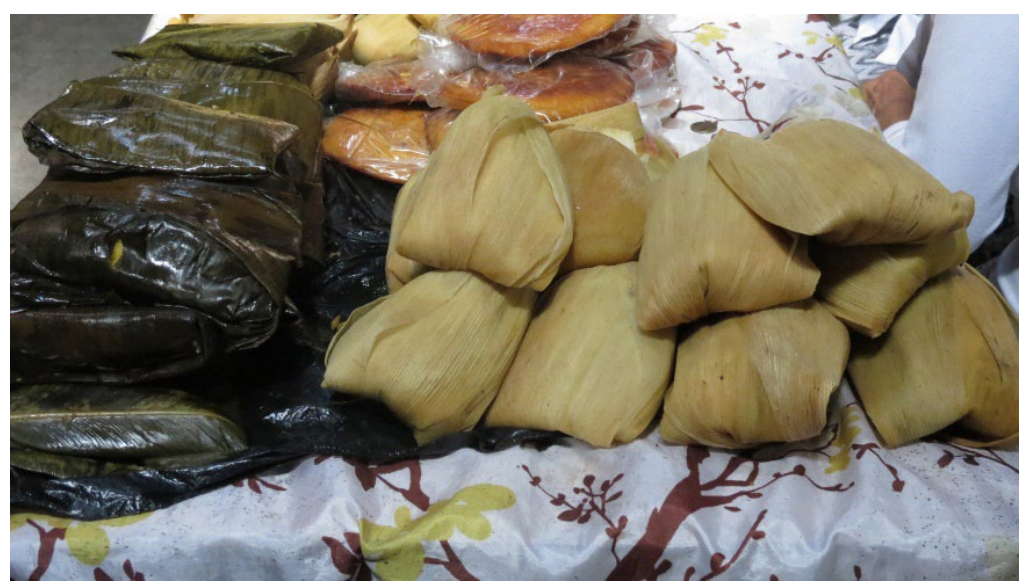

Imagen 2a. Envueltos de maíz. Fuente: Ayda Nidia Ocampo Serna.

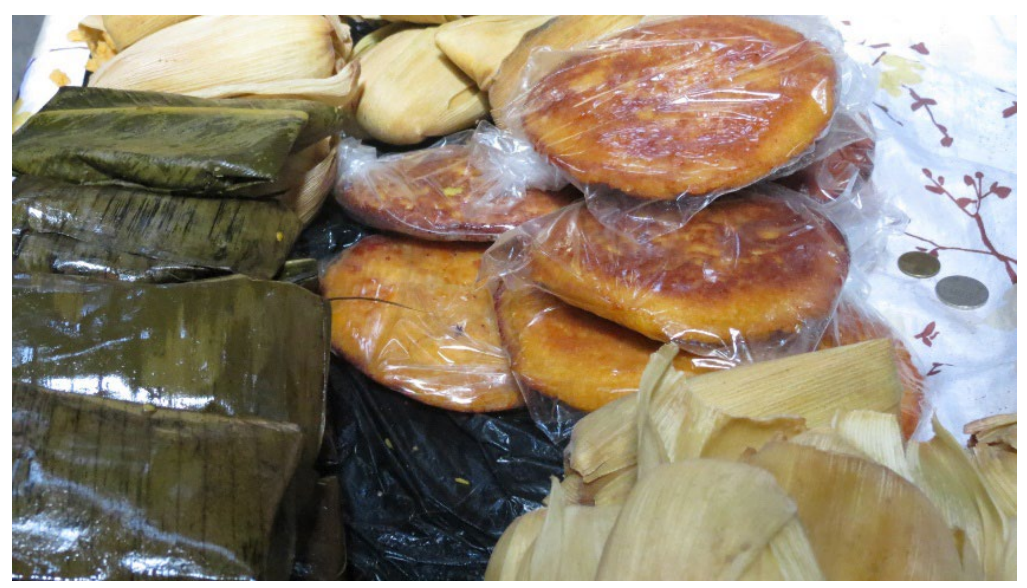

Imagen 2b. Envueltos de Maíz y arepa de chócolo. Fuente: Ayda Nidia Ocampo Serna. 


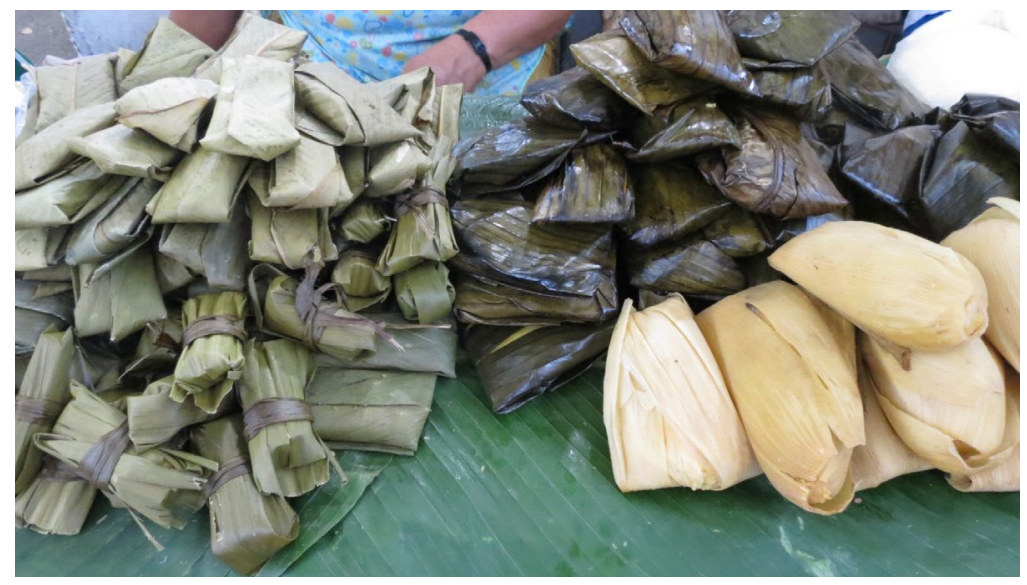

Imagen 3a. Nalgas de Ángel. Fuente: Ayda Nidia Ocampo Serna.

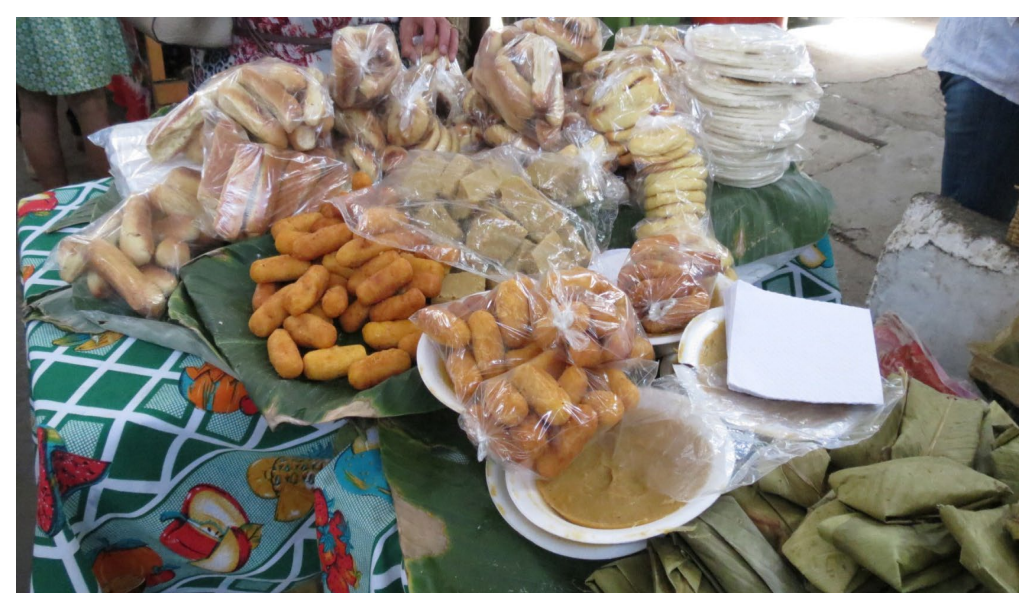

Imagen 3b. Natilla y buñuelos. Fuente: Ayda Nidia Ocampo Serna. 


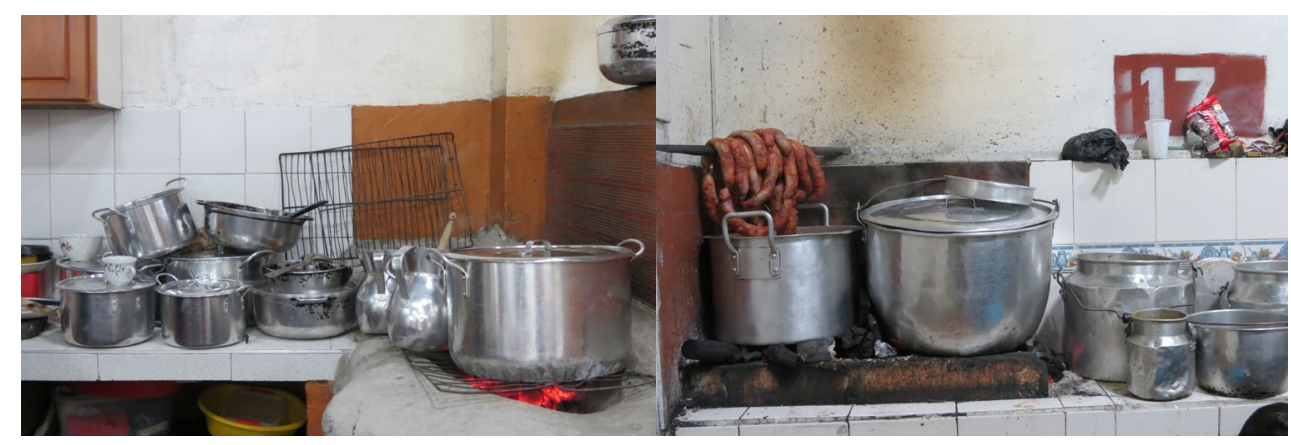

Imagen 4. Cocinas. Fuente: Ayda Nidia Ocampo Serna.

Otro tipo de comida importante en la plaza está representada por la cocina tradicional con más de 25 cocinas (Imagen 4), cada una con un mesón y una banca, donde los comensales pueden sentarse: allí trabajan la cocinera y los ayudantes, generalmente de la misma familia; se cocina con carbón de leña, y en su mayoría están abiertas toda la semana; el menú que ofrecen son platos con productos de la región. Los alimentos están caracterizados por el sabor propio de cada cocina: sancocho de gallina, sopa de mondongo, bandeja picada, hígado, carne asada, lengua sudada, calentado, caldo de pescado, mazamorra, sudado de carne, capón o muchacho entre otros. Otro producto relacionado con la alimentación de la región es la panela, hecha en los trapiches de las veredas y de la cual se derivan algunos dulces vendidos en la plaza como bombones de coco, panelitas de papaya, blanqueados con corozo etc. (Imagen 5). 


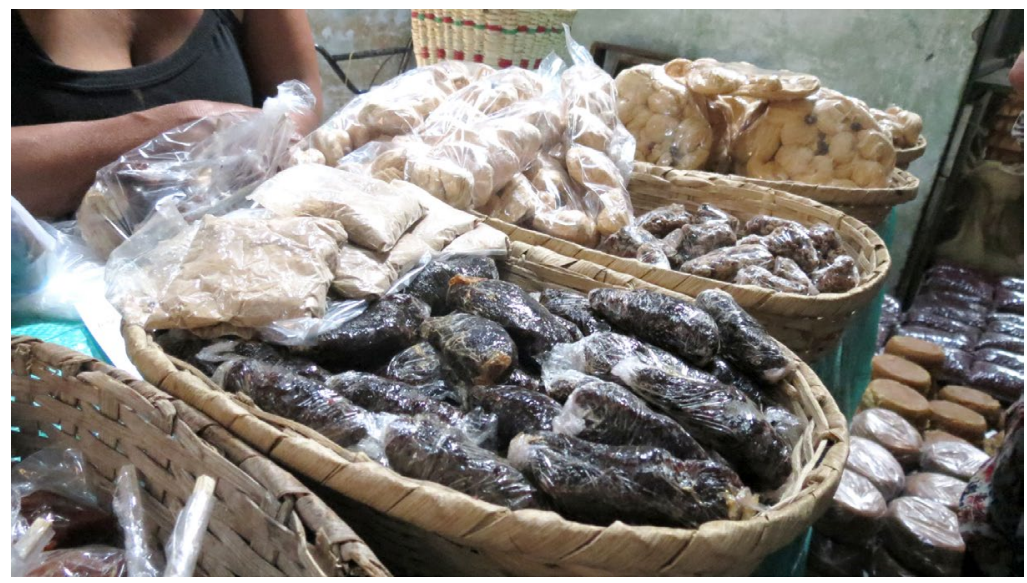

Imagen 5. Dulces derivados de la panela. Fuente: Ayda Nidia Ocampo Serna.

Gracias a las diferentes tradiciones heredadas y aún vivas en la plaza de mercado de Riosucio, se aprecia la riqueza de una cultura culinaria que resalta las relaciones directas entre el comerciante y el consumidor; la ñapa o el encime dejan ver la calidez humana que aún se vive. Asimismo, la diversidad agrícola de la región permite disfrutar de productos y platos. Por tanto, es fundamental exponer que estas tradiciones culinarias requieren ser valoradas para dar paso a proyectos que incluyan emprendimientos culturales que favorezcan la diversidad cultural y la valoración de los saberes construidos alrededor de la cultura culinaria. 


\section{Las industrias creativas y culturales y la inclusión social}

A través de las industrias creativas y culturales se promueven diferentes procesos de inclusión social capaces de empoderar comunidades, no solo en su derecho a acceder a la cultura ${ }^{6}$ y a producirla continuamente, sino también en su rol como actores activos de su propio desarrollo territorial a través de sus recursos creativos y culturales, tanto tradicionales como contemporáneos. Al interior de las comunidades, este empoderamiento genera dinámicas en donde el acceso a la cultura y su producción se convierten en aspectos fundamentales en el fortalecimiento de los recursos creativos y culturales, que conforman la plataforma base para la construcción de sus propias industrias creativas y culturales. Los procesos de acceso y producción permiten sensibilizar a las comunidades sobre su propio acervo cultural (ancestral y contemporáneo) y generar lazos que, además de fortalecer su identidad y sentido de pertenencia, recuperan la confianza en el potencial de los recursos creativos y culturales en procesos de desarrollo territorial.

En el caso del Patrimonio Culinario, la práctica continua de estos oficios es una forma de acceso y producción que se da al interior de las comunidades que heredan estos conocimientos y que debe ser promovida por un sistema institucional para que las mismas comunidades descubran su pertinencia en los diferentes niveles necesarios para su desarrollo y bienestar integral (social, cultural, económico, etc.). Esta iniciativa de acceso y producción también permite a la comunidad portadora, a través de la práctica continua de las cocinas tradicionales, reconocerse como creadora y re-creadora de estas manifestaciones y establecer los parámetros de evolución de estas manifestaciones, teniendo en cuenta que su participación no responde a una

${ }^{6}$ De acuerdo con la UNESCO: "cultural industries are central in promoting and maintaining cultural diversity and in ensuring democratic access to culture" (Cano, Garzón, \& Poussin, 2000, pág. 12). 
formalidad política sino a una evidencia clara de su consentimiento frente a la transformación de su Patrimonio Culinario (UNESCO, 2007), recordando que:

Una verdadera tradición no es el testimonio de un pasado caduco; es una fuerza viva que anima e informa el presente [...] Se establece un vínculo con una tradición para hacer algo nuevo. La tradición asegura de esa manera la continuidad de la creación. (Stravinsky citado en Ministerio de Cultura de Colombia, 2010, p. 187)

En este proceso de inclusión social se potencializa el rol de las comunidades portadoras de saberes culturales en la salvaguardia de sus cocinas tradicionales, ya que ellas mismas —a través de su acceso y producción — promueven su activación y relevancia en el presente y futuro de sus propias comunidades y territorio.

La inclusión social que promueve la Economía Creativa, a través de las industrias creativas y culturales, también se manifiesta al reconocer a la creatividad como su principal eje estructural y como un recurso inagotable que puede ser encontrado en cualquier territorio sin importar su nivel de desarrollo (UNCTAD, 2008). De hecho, el ser humano es un ser creativo por naturaleza sin importar su procedencia (Kelley \& Kelley, 2012) (Sanders E. \& Stappers, 2008) y es esta habilidad la que le permite convertirse en un actor activo de este modelo económico.

Al contar con la participación de las comunidades en la construcción, desarrollo y fortalecimiento de las industrias creativas y culturales, también se promueve su inclusión en su propio desarrollo y bienestar territorial, reconociendo que el entorno funciona mejor cuando las personas afectadas por sus cambios se convierten en actores activos y creativamente participan en su construcción, mejoramiento, gestión, etc. (Sanoff, 2000). 
Este escenario permite a la creatividad canalizarse para promover procesos socio-culturales a través de las industrias creativas y culturales, y también generar oportunidades laborales y económicas como lo afirma el Ministerio de Cultura y el Convenio Andrés Bello (Bello, 2003, pág. 20). "Es decir, no sólo están contribuyendo al desarrollo desde los ámbitos sociales y culturales que les son propios, sino también desde su participación en lo económico".

Por esta razón, a nivel nacional, en el artículo 5 de la ley 1834 de 2017 (por medio de la cual se fomenta la Economía Creativa Ley Naranja) se habla de la inclusión como un aspecto que, en el escenario de las industrias creativas y culturales, puede materializarse a través de mecanismos de circulación de bienes y servicios culturales que entrelazan la democratización del acceso a la cultura, la integración social y la generación de oportunidades laborales y económicas en el sector creativo y cultural.

\section{Las industrias creativas y culturales y su impacto en el crecimiento económico de un territorio}

A nivel internacional, las Industrias Creativas y Culturales han sido reconocidas como motores de desarrollo económico por su impacto en términos de valor agregado, exportaciones, inversiones y aumento de la productividad. Según el informe "Tiempos de cultura: El primer mapa mundial de las industrias culturales y creativas", realizado por la organización Ernst \& Young Global Limited (2015), en el 2013, estas industrias generaron a nivel mundial, 29,5 millones de empleos e ingresos de US \$2,250b, aporte que representó un 3\% del PIB mundial. En este estudio también se especifica el comportamiento de estas Industrias por continentes, resaltando: los 12.7 millones de empleos que genera este sector en Asia Pacífico (principalmente en el área de videojuegos) que corresponden a un $43 \%$ de empleos del sector de la Industrias Creativas y Culturales a nivel mundial; el posicionamiento de Europa como el segundo 
mercado de Industrias Creativas y Culturales más grande del mundo gracias a su gran concentración de sitios reconocidos como patrimonio cultural y a sus numerosas ciudades que hacen parte de la lista de Ciudades Creativas de la UNESCO; el rol del continente Norte Americano liderando la industria del cine, la televisión y la radio; el potencial de Latinoamérica y el Caribe por su gran riqueza cultural y natural (en este momento hay 131 sitios inscritos en la Lista del Patrimonio Mundial de la UNESCO); y el prodigioso crecimiento de la industria cinematográfica de Nollywood en el continente Africano (Ernst \& Young Global Limited, 2015).

En este contexto, Colombia ha tenido un posicionamiento importante desde el 2002 al crear la primera Cuenta Satélite de Cultura ${ }^{7}$ en el mundo. Esta iniciativa fue replicada a partir del 2008 por países como Finlandia y España (Benavente \& Grazzi, 2017). A nivel nacional ha promovido proyectos que buscan apoyar el emprendimiento cultural para el desarrollo, tales como: la Red Nacional de Museos; la Red Turística de Pueblos Patrimonio (El Fondo Nacional de Turismo FONTUR); las Escuelas - Taller; los Laboratorios Sociales de Emprendimiento Cultural - LASO; el Grupo de Emprendimiento Cultural del Ministerio de Cultura; y la Ley Naranja que fomenta la Economía Creativa, entre otros.

Estos esfuerzos se reflejan en las estadísticas recopiladas del 2013 al 2016, que muestran que estas industrias con su aporte del 3,3\% al PIB nacional están por encima de la participación en el PIB que realiza el sector del café y el de la minería; además de haber generado 1,1 millones de empleos, que representan alrededor del 5\% del total de ocupados en el país (González \& Sánchez, 2018).

${ }^{7}$ Mecanismo gubernamental que recopila información acerca del sector de las industrias creativas y culturales en una nación, con el fin de hacer un seguimiento que permita determinar los beneficios de la economía naranja. 


\section{Conclusiones}

Este marco teórico permite dirigir las conclusiones al potencial que presenta la cultura culinaria de la plaza de mercado de Riosucio (Caldas) en el planteamiento de un emprendimiento cultural para el desarrollo territorial.

Las plazas de mercado, articuladas de forma inevitable a la cultura culinaria de un territorio, presentan un escenario de emprendimiento cultural que, por lo general, se conecta con el sector del turismo cultural. Casos como los que se presentan en innumerables plazas de mercado europeas, resaltan la importancia del turismo en su sostenibilidad al generar recursos que permiten la conservación de su patrimonio material (arquitectura) e inmaterial (como las tradiciones agrícolas de un territorio y la elaboración de platos tradicionales), además de generar empleos en las mismas comunidades herederas de estos bienes culturales. De esta manera, el patrimonio culinario presente en estos lugares trasciende los límites del pasado, se fortalece a través de su práctica diaria como un proceso de producción cultural, y adquiere un rol activo en la calidad de vida de las nuevas generaciones.

Sin embargo, también se presentan casos en donde el turismo cultural descontrolado ha generado daños irreversibles a los sitios patrimoniales, al olvidar la importancia de respetar su autenticidad sociocultural, no solo por tratarse de un aspecto que hace de estos lugares portadores de una identidad única y excepcional que además es "worth seeing" (factor crucial en el fomento del turismo), sino también por su rol en el entendimiento y la tolerancia frente a la diversidad cultural (Ministerio de Cultura de Colombia, 2010).

Este escenario ha generado bastantes controversias frente al tema del turismo en lugares de interés cultural, y es por esto que la política para el conocimiento, la salvaguardia y el fomento de la alimentación y las cocinas 
tradicionales de Colombia enfatiza en, su estrategia 3, la importancia de desarrollar emprendimientos de turismo cultural y comunitario que manejen de manera respetuosa y responsable las tradiciones culinarias. Este interés interconecta el desarrollo de emprendimientos de turismo gastronómico con la estrategia 1 de esta política, la cual enfatiza sobre la importancia de generar procesos de reconocimiento, valoración y enseñanza de este patrimonio en las mismas comunidades portadoras de estos conocimientos y prácticas, que les permitan entender el valor de estas tradiciones; la necesidad de manejarlas de forma respetuosa; y la importancia de transmitir a los visitantes (locales, nacionales, internacionales, estudiantes de colegios y universidades) su valor desde un conocimiento sólido sobre este patrimonio (Ministerio de Cultura de Colombia, 2012).

A partir de este marco teórico y legal, se establecen unas bases generales para el desarrollo de un emprendimiento de turismo comunitario en la plaza de mercado de Riosucio (Caldas), que desde la valoración del conocimiento y prácticas de la cocina tradicional (que haga la misma comunidad) permita un desarrollo territorial que integre la producción cultural continua de estos saberes, la inclusión social, la generación de empleos y crecimiento económico.

Esta propuesta proyecta a la plaza de mercado como un nodo de experiencias gastronómicas y de conocimiento en torno a la cultura culinaria de un territorio, capaz de iniciar la construcción de una red de plazas de mercado del eje cafetero (región en donde se encuentra la plaza de Riosucio), que promueva el turismo cultural de forma articulada a las experiencias y saberes sobre las cocinas tradicionales en las comunidades portadoras de este patrimonio y en los visitantes.

El planteamiento desarrollado a lo largo de esta tesis, busca generar un aporte para futuras iniciativas que a partir del reconocimiento del patrimonio 
culinario de la Plaza de Mercado de Riosucio (Caldas) como recurso de desarrollo cultural, social y económico promueva proyectos que le permitan a estas manifestaciones trascender la esfera local y simbólica para convertirse en manifestaciones que las mismas comunidades reconozcan como fuente de intercambio e innovación, además de promotoras del florecimiento de la existencia humana en todas sus formas (UNCTAD, 2013).

\section{Agradecimientos}

A la comunidad de la plaza de mercado de Riosucio. A las portadoras del conocimiento culinario.

\section{Referencias}

Arista Zerga, A. (2015). La cocina, patrimonio cultural del Perú. Em R. Ávila, M. Álvarez, \& F. X. Medina, Alimentos, cocinas e intercambios culinarios. Confrontaciones Culturas, identidades, resignificaciones. (pp. 187-204). México: Universidad de Guadalajara.

Bello, C. A. (2003). Impacto Económico de las Industrias Culturales en Colombia. Bogotá: Unidad Editorial.

Benavente, J., \& Grazzi, M. (2017). Public Policies for Creativity and Innovation: Promoting the Orange Economy in Latin America and the Caribbean.

Cámara de Comercio de Manizales. (1999). Monografía de Riosucio. Riousucio: Cámara de Comercio de Manizales.

Cano, G. A., Garzón, A., \& Poussin, G. (2000). en.unesco.org. Fonte: https://en.unesco.org/creativity/sites/creativity/files/culture_trade_and_ globalisation.pdf 
Caraballo, C. (2011). Patrimonio Cultural. un enfoque diverso y comprometido. México: UNESCO.

Ernst \& Young Global Limited. (2015). Tiempos de cultura: El primer mapa mundial de las industrias culturales y creativas.

González, C., \& Sánchez, N. (2018). Cuadernos de Desarrollo Económico. Información Económica de las Industrias Creativas y Culturales en Bogotá. Bogotá D. C.: Secretaría de Desarrollo Económico de Bogotá.

Grandma's Desing. (09 de 05 de 2015). http://www.grandmasdesign.com/. Fonte: Grandma's Desing: http://www.grandmasdesign.com/

Hernández, O. (2006). El paladar de los caldenses. Manizales: Edigráficas.

Howkins, J. (2002). The creative economy: How people make money from ideas. UK Penguin.

ICOMOS 14th General Assembly and Scientific Symposium. (2003). INTANGIBLE CULTURAL HERITAGE INVOLVED IN TANGIBLE CULTURAL HERITAGE Nobuo ITO*, Japon / Japan. Zimbabwe: ICOMOS.

Instituto Nacional de Patrimonio Cultural de Ecuador. (2013). Guía metodológica para la salvaguardia del Patrimonio Cultural Inmaterial. Quito: INPCE.

Kelley, T., \& Kelley, D. (2012). Reclaim your creative confidence. Harvard business review, 12(90), 115-118.

Largo, C. (2017). Receta de cocina tradicional en persona. (A. N. Ocampo, Entrevistador) Riosucio.

Lauer, M., \& Lauer, V. (2006). La revolución Gastronómica Peruana. Lima: Universidad de San Martín de Porres. 
Miele, M., \& Murdoch, J. (1999). Back to Nature: Changing worlds of production in the food sector. European Society for Rural Sociology Ruralis, 39, 465-483.

Ministerio de Cultura de Colombia. (2012). Política para el conocimiento, la salvaguardia y el fomento de la alimentación y las cocinas tradicionalesde Colombia. Bogotá: Ministerio de Cultura.

Montoya. A. M. M. \& Piedra, G. F. (2017). Mediciones Culturales. Resultados del proyecto: Elaboración e implementación de la Cuenta Satélite de Cultura, CSC, en los países del área andina. Observatorio Iberoamericano de Cultura website

R., S. (2012). Juntos. Riuales, Placeres y Política de Cooperación. Barcelona: Anagrama.

Sanders E., B. N., \& Stappers , P. J. (2008). Co-creation and the new landscapes of design. Co-design, 4(1),, 4(1), 5-18.

Sanoff, H. (2000). Community participation methods in design and planning. John Wiley \& Sons.

Sennett, R. (2012). Juntos. Rituales, placeres y política de cooperación. Barcelona: Anagrama.

Throsby, D. (2001). Economics and Culture. Cambridge: Cambridge University Press.

Torricelli, O. (27 de Octubre de 2014). Carlo Petrini: en América Latina, ha surgido una revolución gastronómica. Fonte: Radio Francia InternacionalEspañol: http://www.espanol.rfi.fr/americas/20141027-en-america-latinaha-surgido-una-revolucion-gastronomica

UNCTAD. (2008). unesco.org. Fonte: https://unctad.org/system/files/officialdocument/ditc20082cer_en.pdf 
UNCTAD. (2013). unesco.org. Fonte: http://www.unesco.org/culture/pdf/ creative-economy-report-2013.pdf

UNESCO. (1998). www.lacult.unesco.org. Fonte: http://www.lacult.unesco. org/docc/1998_Action_Plan_Cultural_Policies_for_Dev_UNESCO.pdf

UNESCO. (2003). Convención para la Salvaguardia del Patrimonio Cultural Inmaterial . Paris: Unesco.

UNESCO. (2007). Fonte: unesdoc.unesco.org: http://unesdoc.unesco.org/ images/0014/001497/149708e.pdf

Zapata Bonilla, J. E. (1997). Visión del Occidente de Caldas. Supía: Gráficas Lancheros.

Nota: se recomienda citar así:

Cómo citar: Ocampo, A. N. y Delgado, T. (2021). El patrimonio culinario como generador de industrias creativas y culturales: el caso de la plaza de mercado de Riosucio, Caldas, Colombia. Revista KEPES, 18(23), 147-177. https://doi.org/10.17151/kepes.2021.18.23.6 